\title{
Grand Rounds: A Method for Improving Student Learning and Client Care Continuity in a Student-Run Physical Therapy Pro Bono Clinic
}

\author{
Jill D. Black, PT, DPT, EdD ${ }^{1}$, Kyle N. Bauer, DPT, Georgia E. Spano, DPT, Sarah A. Voelkel, \\ DPT, Kerstin M. Palombaro, PT, PhD, CAPS
}

\begin{abstract}
Background and Purpose. Grand Rounds is a teaching methodology that has existed in various forms in medical education for centuries. When a student-run pro bono clinic identified a growing challenge of providing continuity of care for clients and a lack of preparedness in students, they implemented a Grand Rounds model of case presentation within the curriculum. The purpose of this paper is to describe the implementation and assessment of Grand Rounds as it attempts to improve both the continuity of care for the clients and the learning experience for the students involved in a student-run pro bono clinic.

Case Description and Evaluation. The Student Board divided the student physical therapists and the clients into three teams. Each team of students would meet every three weeks to discuss the clients on their caseload. More advanced students helped to mentor the more novice students and a faculty member would facilitate the discussions.

Outcomes. After eight months of implementation, the Student Board gathered evaluative data from students, supervisors and client. The Widener University Institutional Review Board approved the program evaluation. Analysis of the data collected revealed that the students grew more confident and effective in their ability to implement and advance the physical therapy program.

Discussion and Conclusion. The program evaluation confirmed that the implementation of teams and Grand Rounds positively impacted students' confidence and ability to collaboratively treat and advance clients and their physical therapy program in the student-run pro bono clinic. The program evaluation was not effective in thoroughly assessing the impact that the model had on clients and their recovery. Further evaluation should be conducted with client outcomes measures. Recommendations for the modification and improvement of Grand Rounds emerged.
\end{abstract}

Keywords: grand rounds, case presentations, mentorship, student-run pro bono clinic.

\footnotetext{
${ }^{1}$ All of the authors are affiliated with Widener University, One University Place, Chester, PA 19013
} 


\section{Background and Purpose}

Grand Rounds is traditionally defined as "rounds involving the formal presentation by an expert of a clinical issue sometimes in the presence of selected patients" (Merriam Webster Dictionary, 2015). Grand Rounds has its roots in medical residency training as an educational method for introducing new material and enhancing clinical reasoning through discussion of authentic client cases (Medicine Net 2015). Historically, Jean Martin Charcot is credited with the initiation of Grand Rounds (Goetz, Bonduell, Gelfand, Charcot, 1995). In the late 1800s, he routinely delivered extensive neurological case presentations to an audience of physicians, students, family members, and other interested members of the public. Typically, his patient was present for the case presentation as a visual aid. The purpose of the case presentation was to share his expertise and to advance the care of the patient (Goetz, Bonduell, Gelfand, Charcot, 1995).

Grand Rounds remained a staple of medical education for years, but concerns for patient dignity and confidentiality led to the practice of conducting Grand Rounds without the patient present (Stanyon \& Khan, 2015). In time, the Grand Rounds format shifted away from case based presentations and evolved into an expert lecture with an emphasis on the latest evidence (Hebert \& Wright, 2003). This version of Grand Rounds is largely didactic with little opportunity for audience engagement. Hull, Cullen, and Hekelman (1989) researched the implementation of Grand Rounds is the late 1900s. They noted that Grand Rounds provided continuing medical education credit as well as a forum for the socialization of medical students. The medical culture was perpetuated as experienced physicians provided examples of problem-solving techniques, values, application of evidence, and presentation of cases.

A 2001 survey of US hospitals with medical residency programs found that Grand Rounds were offered in $97 \%$ of 300 respondent hospitals. The most important objectives of these contemporary Grand Rounds were to educate audience members, showcase faculty role models, and to promote a collegial atmosphere. The formats were largely lecture-based and patients were present less than 3\% of the time. Of all of the Grand Rounds, only $10 \%$ represented clinical case presentations and overall, opportunities for learner participation or interaction were minimal (Hull, Cullen \& Hekelman, 1989).

In 2009, Van Hoof, Monson, Mafdalany, Giannotti \& Meehan conducted an in-depth qualitative investigation of Grand Rounds at a particular medical institution. The researchers observed 16 Grand Rounds presentations and conducted interviews and focus groups with key informants from the audience, the presenters, and the planners. Similar to Hebert and Wright's findings (2003), the Grand Rounds lacked active participation or input from the learners. The presentations were didactic and the audience assumed a very passive role.

Distinct from Grand Rounds are the historical practice of "ward rounds" which is the term typically used to describe the activity of a team of physicians, residents, and/or medical students visiting clients in the hospital as a daily routine (Parissopoulos, Timmins \& Daly, 2013). Ward rounds focused first on the needs of the client and second on the needs of the student. Recent research around the educational value of ward rounds found that "the main obstacles to effective learning and teaching were lack of time, number of patients, frequent interruptions, lack of interest from seniors, and the relationship between seniors and juniors" (Laskaratos, Wallace, Gkotsi, Burns \& Epstein, 2015). Ward rounds returns the focus to case-based learning but this article found that they may not be the optimal venue to meet the educational needs of the student.

The challenge is to find an optimal education method to facilitate student learning while simultaneously enhancing patient care. An article in recent medical education literature describes a monthly Grand Rounds meeting where first through fourth year medical students met to produce

Journal of the Scholarship of Teaching and Learning, Vol. 17, No. 3, July 2017. josotl.indiana.edu 
concept maps that linked together curricular content in their medical education across four years. The researchers held focus groups for students from each year to determine their impressions and perceptions of participating in the case conferences. The Grand Rounds was found to increase the interaction of students across classes, encourage students to develop as peer teachers, and strengthen links between pre-clinical and clinical course content. The cases discussed were fictitious and were created only for the learning experience (Richards, Schwartzstein, Irish, Almeida \& Roberts, 2013).

Rigby, Schofield, Mann \& Bernstead (2012) describe a contemporary Canadian format for Grand Rounds that has returned to the case-based presentation practice by Charcot, but with incorporation of a more active based pedagogy. In this model, a resident presents a case and attendees are encouraged to participate by asking questions, providing feedback, offering suggestions. A staff physician typically serves as moderator, charged with engaging the audience in discussion and providing expert guidance as needed. Rigby, Schofield, Mann \& Bernstead (2012) sought to identify elements that contributed to a highly educational Grand Rounds experience and conducted a Delphi study of 32 physician experts involved in these Canadian Grand Rounds. Three rounds of questionnaires were completed and the researchers found strong support for case based rounds, high level of audience interaction, and resident participation in case presentation and analysis. This form of Grand Rounds retains the case-based presentation that serves to enhance client care as well as an active learning pedagogy that facilitates student collaborative learning.

Students of the Widener University Institute for Physical Therapy Education encountered client continuity and case progression challenges that they thought might be remedied by the additions of Grand Rounds as described by Richards, Schwartzstein, Irish, Almeida \& Roberts (2013) and Rigby, Schofield, Mann \& Bernstead (2012). The students had been treating clients from Chester, PA and surrounding communities in the student-run pro bono physical therapy clinic, the Chester Community Physical Therapy (Clinic) for five years. With 100\% student participation from all three classes, as many as 150 students are circulating through the clinic treating a pool of 20-25 clients at any given time. This had led to difficulty with continuity and progression of client programs. Students proposed breaking themselves and their clients into teams and establishing a regular schedule of rotating team Grand Rounds where student team members could discuss client cases on their teams every three weeks. The purpose of this paper is to describe the implementation of teams and Grand Rounds and to assess the effectiveness of the method as it attempts to improve both the continuity of care for the clients and the learning experience for the students.

\section{Case Description and Evaluation}

Students of the Widener University Institute for Physical Therapy Education treat uninsured and underinsured clients from the Chester community and surrounding areas in the student-run pro bono physical therapy Clinic under the supervision of licensed physical therapists. The Clinic's mission statement is:

"to simultaneously improve healthcare access to physical therapy services by providing pro bono services to the underserved and underinsured population in the surrounding community while educating a new generation of physical therapists in the areas of competency, character, citizenship, and social responsibility.” (Chester Community Physical Therapy Clinic, 2016)

Journal of the Scholarship of Teaching and Learning, Vol. 17, No. 3, July 2017. josotl.indiana.edu 
The Clinic is run by a Student Board consisting of 12 board positions with representatives from all three classes of students (see Figure 1). While the Student Board oversees the operations of the Clinic, every physical therapist student in the Institute for Physical Therapy Education at Widener University serves at least four nights / semester; therefore, all physical therapist students have an active role treating in client care.

$\mathrm{X}$

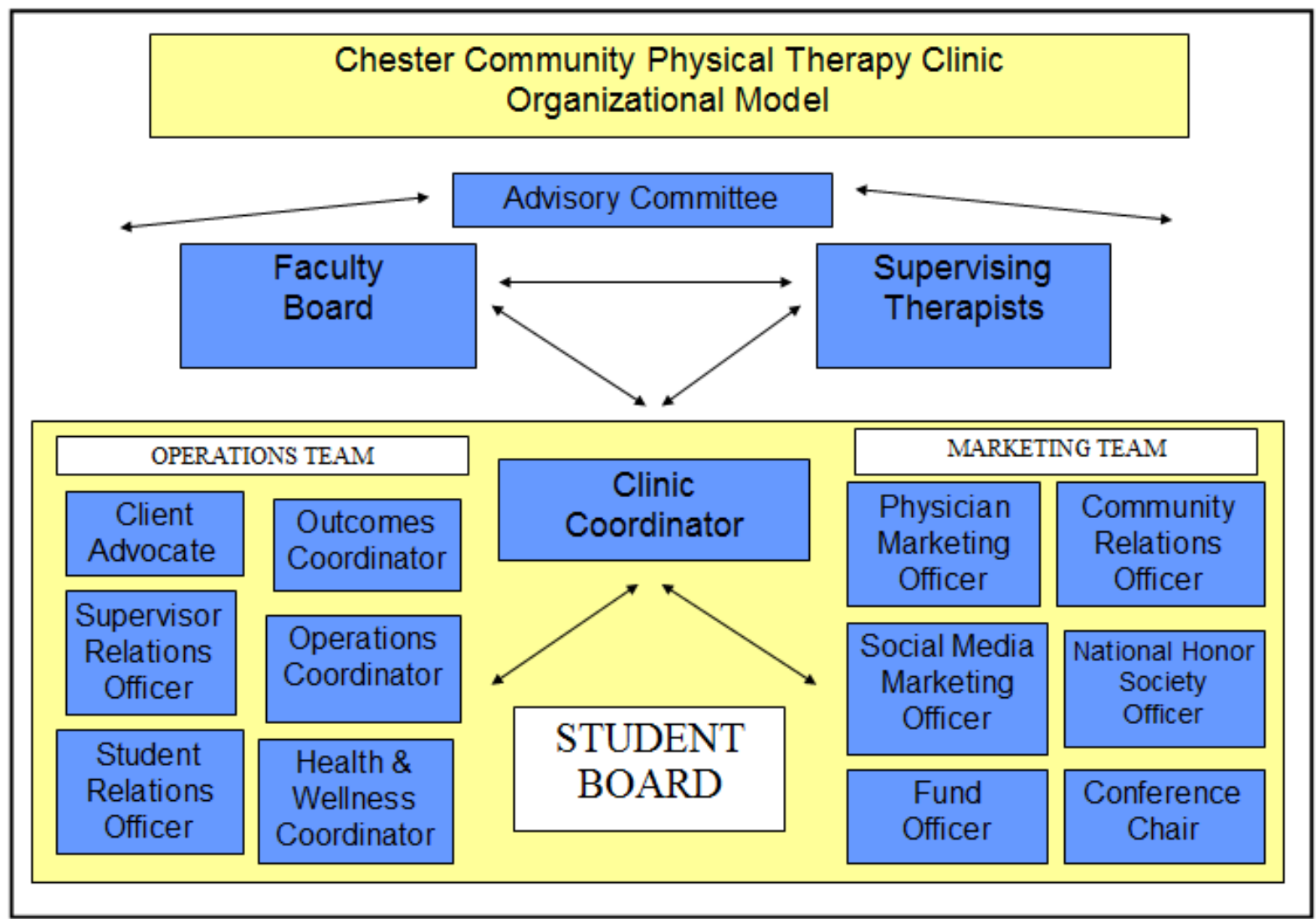

Figure 1. Organizational Chart of the Chester Community Physical Therapy Clinic and the Student Board

The Clinic is open four evenings / week throughout the entire year. Students across three years of the Doctor of Physical Therapy (DPT) curriculum take turns serving in the clinic always under the licensed supervision of physical therapists. The licensed supervisors include full-time faculty members, adjunct faculty members, and local physical therapists, many of whom are alumni of the program and served in the Clinic as students previously. The students participate in client care in accordance with their level of education in the curriculum. For example, the students in their first semester learn general principles of client interviews, how to take vital signs, and basic therapeutic exercise and basic transfer and gait training intervention. The first-year students are expected to assist in client care in these areas and do so under the mentorship of second and third-year students and ultimately supervised by the licensed physical therapists onsite. In their second semester, they learn basic tests and measures and begin to contribute to the Clinic with 
application of these skills. Second-year students possess the skills to conduct a complete evaluation or re-evaluation but require guidance and mentorship with establishing goals and determining progression. Third-year students bring the higher-level skills of manual techniques and managing complexity. They serve as peer mentors for the first and second-year students. Students throughout all three years of the curriculum participate in documentation. All of this occurs under the direct supervision of the licensed physical therapists and faculty onsite each evening in the clinic.

Throughout the three-year curriculum, the DPT students are sometimes off campus for their full time clinical experiences and are not able to participate in the Clinic in this time. Table 1 depicts the months that each Class of students are on campus and participating in the Clinic.

\section{Table 1. Rotation of Students Participating in the Clinic throughout the Curriculum}

\begin{tabular}{|l|l|l|l|l|l|l|l|l|l|l|l|l|}
\hline & Jun & July & Aug & Sept & Oct & Nov & Dec & Jan & Feb & March & April & May \\
\hline $1^{\text {st }}$ & & & & & & & & & & & & \\
Year & & & & & & & & & & & & \\
\hline $\begin{array}{l}2^{\text {nd }} \\
\text { Year }\end{array}$ & & & & & & & & & & & & \\
\hline $\begin{array}{l}3^{\text {rd }} \\
\text { Year }\end{array}$ & & & & & & & & & & & & \\
\hline
\end{tabular}

Table Legend

\begin{tabular}{|l|l|}
\hline & $\begin{array}{l}\text { Students are off campus and not available to } \\
\text { participate in the pro bono clinic }\end{array}$ \\
\hline $\begin{array}{l}\text { Students are on campus and are } \\
\text { participating in the pro bono Clinic }\end{array}$ \\
\hline
\end{tabular}

The program begins in June of the first-year with a full-time10-week anatomy course that is off campus. The second-year students have a full-time clinical experience and are off campus April through August. They return to campus for September and October as third-year students before leaving for their two full-time clinical experiences that occur from November through to graduation in May. The students are considered to advance in the program every June.

The Clinic is open for two hours each night and services an average of 6-10 clients / night. Student physical therapists sometimes expressed to Student Board members that they felt unprepared to treat unfamiliar clients at the Clinic. While they had 30 minutes prior to client arrival to conduct a chart review with the assistance of the licensed physical therapists onsite for the evening, they still felt lost and inadequately prepared to understand and confidently advance the client's program. While students were expressing a sense of unpreparedness, clients noted that they rarely saw the same student therapist twice. Clients remarked favorably when there was therapist consistency in their treatments. Additionally, the licensed physical therapy supervisors serving in the Clinic had communicated that students generally struggled with program progression and discharge planning.

In an attempt to provide better continuity of care for the clients as well as a stronger learning experience for the students, the Student Board members of the Clinic suggested the 
formation of teams and the implementation of a Grand Rounds-type review of client cases. They approached faculty for help in designing something that would be mutually beneficial to students as well as clients and be mandated within the curriculum. Simultaneously, the faculty were in the midst of curriculum change and had an opportunity for the integration of something new within the curriculum. Together, the Student Board and faculty designed a two-credit course that would be called PT770: Grand Rounds. The objectives are listed in Table 2.

\section{Table 2. Objectives for PT770: Grand Rounds}

1. Participate in the design and implementation of best clinical practice for pro bono clients

2. Demonstrate professional behavior and effective communication skills within the team setting

3. Provide mentorship to peers in an effective manner

4. Demonstrate improved clinical decision making skills by using clinical judgment and reflection to identify, monitor, and enhance client programs

5. Apply current knowledge and professional judgment while considering the client perspective in client management

6. Identify, respect, and act with consideration for client differences, values, and preferences when designing and advancing programs.

In order to effectively implement Grand Rounds in a manageable fashion, the Student Board created teams of students and clients. They divided the three student classes into three equal groups and assigned them to Team A, Team B, or Team C. Each student team had an equal number of first, second, and third-year students, allowing for mentorship within the teams. The Student Board also assigned the active Clinic clients to Team A, B, or C. A range of 5-8 clients was on a team at any given time during the duration of the trial period. A total of three students per team (one student per class) were scheduled at the Clinic to treat their respective clients each evening. Table 3 shows a fictitious structure of the student and client schedule for a night of Clinic operation in the beginning of the fall semester when all three classes of students are on campus. 
Black, Bauer, Spano, Voelkel, and Palombaro

Table 3. Fictitious Sample Schedule

\begin{tabular}{|l|c|c|c|}
\hline $\begin{array}{l}\text { Pre-PT } \\
\text { Receptionist }\end{array}$ & \multicolumn{3}{|c|}{ Amanda (pre-PT work study student) } \\
\hline $\begin{array}{l}\text { Student Board } \\
\text { Administrators }\end{array}$ & \multicolumn{3}{|c|}{ Daria (PT3) \& Nolan (PT2) } \\
\hline $\begin{array}{l}\text { Licensed } \\
\text { Supervisors }\end{array}$ & \multicolumn{3}{|c|}{ Wayne (adjunct faculty) and Mark (full-time faculty) } \\
\hline & TEAM A & TEAM B & TEAM C \\
\hline Student Teams & Jess (PT3) & Nicole (PT3) & Kyle (PT3) \\
& Amanda (PT2) & Scott (PT2) & Thyati (PT2) \\
& Tim (PT1) & Brittany (PT1) & Tom1) \\
& Team A Client & Team B Client & Team C Client \\
\hline $\mathbf{4 : 3 0}$ & Team A Client & - & Team C Client \\
\hline $\mathbf{5 : 0 0}$ & Team A Client & Team B Client & Team C Client \\
\hline $\mathbf{5 : 3 0}$ & $\ddots$ & - & - \\
\hline $\mathbf{6 : 0 0}$ & - & - & - \\
\hline $\mathbf{6 : 3 0}$ & &
\end{tabular}

Note that two licensed physical therapists (in this case one full-time faculty and one adjunct faculty member) provide the supervision. The third-year PT students provide mentorship for the first and second-year students. The team of students determines how they will handle the clients on the schedule and will work together within the skill sets that they have to provide the service. For instance, the first-year students will be expected to greet the clients and take their vital signs. The second and third-year students will be responsible for program progression, higher-level skills and assessments. The first-year students, however, will be alongside the session and will be learning from the second and third-year students throughout. The two faculty members provide the needed supervision and direction. Much like clinical education, the amount of direction and close supervision needed depends on the skill levels of the students at the time. By the time they are third-year students, more distant supervision is acceptable. When the third-year students are off campus and the second-year students are mentoring the first-year students, more direct supervision from the faculty member or licensed physical therapy clinician is needed. The clinic space consists of two wide-open spaces with curtains that can be drawn for privacy as needed. The openness of the space provides for ease of supervision by the faculty and licensed physical therapy supervisors.

The addition of the Grand Rounds course provides an additional forum to prepare students for treating the clients in the Clinic. The faculty designed two-credit course spans five semesters, allowing students to participate across all three years in the curriculum. With the guidance of an adjunct faculty member, each team of students met for one hour every third week to discuss the clients on their team. Students from the second-year class would sign up to give a case presentation for a client whom they had recently evaluated or treated. The second-year student would present his or her case and open up the opportunity for discussion and questions. Case presentations average five minutes / case. Some cases require less time and some more. A template to guide the case presentation helps the student cover key components in an efficient manner and is included in Appendix A. The adjunct faculty member would facilitate the discussion and would encourage 
demonstration and instruction of unfamiliar concepts or interventions. The course was designed as a pass / fail course with student attendance and participation required for passing.

We initiated the teams and Grand Rounds course at the start of the summer session in May. This meant that only the second-year students were on campus and were the only class serving in the clinic and participating in Grand Rounds until the start of the fall semester in September. From September onwards, all three classes of students were on campus and participating in both the Clinic and in Grand Rounds. In Grand Rounds, the second-year students continued to take the lead in the case presentations while the third-year students served as mentors, contributing their knowledge from their recent full-time clinical experience. The first-year students attended but were not expected to actively participate. They were told to listen and absorb what they could of the cases presented. We evaluated the effectiveness of the implementation of teams and Grand Rounds after an eight-month time period, May through to December. In this period, each team met for Grand Rounds a total of seven times. A faculty member and six second-year Student Board members analyzed the outcome data which included surveys of first and second-year students, reflections of third-year students, interviews with clinical supervisors, and analysis of client satisfaction surveys. The Widener University Institutional Review Board approved the evaluation plan.

\section{Outcomes}

Participants in the evaluation included 45 first-year students, 42 second-year students, and 43 thirdyear students. Four clinic supervisors who volunteered at the Clinic both before and after the implementation of Grand Rounds, and 16 client satisfaction surveys, which encompassed clients who had received therapy both before and after the implementation of Grand Rounds, were also part of the evaluation.

Retrospective Reflective Paragraphs from Third-Year Students.

The third-year students participating in Grand Rounds were required to submit a reflection of their experience in Grand Rounds as part of their PT715 Teaching and Learning class. They provided informed consent to use their reflection in the evaluation. The statement to guide the reflection is included in Appendix B. Student reflections were de-identified prior to review. Two of the Student Board members reviewed the reflections and noted recurring themes.

\section{Second-year student pre and post surveys}

The second-year students were informally surveyed by two of the Student Board members before and 8 months after the implementation of Grand Rounds. The electronic survey was created by the two Student Board members and students completed the survey anonymously via Survey Monkey. The survey consisted of 5 questions asking the students to rate their confidence on a 5point Likert scale. A copy of the survey is included in Appendix C. A Wilcoxon Signed Ranks test was used to analyze the data given that it was a non-parametric data set. The significance was rated on a p value of $<0.05$. See Table 4 for a complete presentation of the statistics for each of the five questions. 
Table 4: Second-year Physical Therapy Student Survey

\begin{tabular}{|c|c|c|c|c|c|c|c|c|c|c|}
\hline \multirow[t]{2}{*}{$\begin{array}{l}\text { Question } \\
\text { Asked }\end{array}$} & \multicolumn{2}{|c|}{$\begin{array}{l}\text { Knowledge } \\
\text { of patient's } \\
\text { condition }\end{array}$} & \multicolumn{2}{|c|}{$\begin{array}{l}\text { Amount of } \\
\text { prep time }\end{array}$} & \multicolumn{2}{|c|}{$\begin{array}{l}\text { Understanding } \\
\text { of patient } \\
\text { progression }\end{array}$} & \multicolumn{2}{|c|}{$\begin{array}{l}\text { Confident } \\
\text { in altering } \\
\text { patient's } \\
\text { POC }\end{array}$} & \multicolumn{2}{|c|}{$\begin{array}{l}\text { Confident } \\
\text { in treating } \\
\text { the } \\
\text { patient's } \\
\text { pathology }\end{array}$} \\
\hline & Pre & Post & Pre & Post & Pre & Post & Pre & Post & Pre & Post \\
\hline Means & 3.25 & 4.09 & 3.61 & 4.00 & 2.75 & 3.76 & 2.92 & 3.97 & 3.42 & 4.03 \\
\hline $\begin{array}{l}\text { Standard } \\
\text { Deviation } \\
\text { (pre-post) }\end{array}$ & 0.89 & 0.75 & 0.79 & 0.95 & 0.76 & 0.89 & 1.04 & 0.97 & 0.68 & 0.78 \\
\hline $\begin{array}{l}\text { Wilcoxon } \\
\text { Signed } \\
\text { Ranks Test } \\
\text { Significance }\end{array}$ & \multicolumn{2}{|c|}{0.01} & \multicolumn{2}{|c|}{0.03} & \multicolumn{2}{|c|}{0.01} & \multicolumn{2}{|c|}{0.01} & \multicolumn{2}{|c|}{0.03} \\
\hline
\end{tabular}

Likert Scale (5= Strongly agree; 4= Agree; 3= Neither agree or disagree; 2= Disagree; $1=$ Strongly disagree), $\mathrm{n}=42$ $\mathrm{p}<0.05$ is found to be significant change

\section{First-Year Student Participation Reflection}

First-year students gave informed consent and completed an anonymous reflection via Survey Monkey regarding their participation in Grand Rounds. The reflection questions were created by two Student Board members and are included in Appendix D. Two Student Board members individually read the responses and then collaborated to discuss recurring themes.

Interviews of Clinic Supervisors

Four clinic supervisors gave informed consent and participated in an interview by one of the Student Board members. Interviews were de-identified and transcribed onto a Microsoft Word document. Responses were first read individually by two of the Student Board members to identify recurring themes and then reviewed with all researchers to discuss findings. A copy of the supervisor interview form is included in Appendix E.

\section{Client Satisfaction Surveys}

The treating physical therapy students routinely administer client satisfaction surveys at the client's initial evaluation, re-evaluation, and discharge visits. The Health and Wellness 
Coordinators of the Student Board collect them anonymously. The client satisfaction surveys are separate from, and are in no way linked to, the medical record. With the implementation of Grand Rounds, the client satisfaction survey was altered to include questions designed to obtain client feedback in regards to the initiation of teams and Grand Rounds. Two of the Student Board members reviewed and analyzed the client satisfaction surveys of clients who had been treated in the Clinic pre and post Grand Rounds implementation. The client satisfaction survey is included in Appendix F.

Upon initial review of all of the data by pairs of Student Board members, the evaluating team came together with the faculty member and did a comprehensive review of all of the data, looking for repeated and relevant themes. The five data points were triangulated by the evaluation team to provide an assessment of the effectiveness of Grand Rounds in improving student learning and client case progression and satisfaction. After examination and re-examination, they agreed that the five data points supported three major themes. Those three themes were confidence, teamwork, and continuity.

\section{Confidence}

Four of the data points strongly supported the theme of confidence. The pre and post surveys administered to the second-year students revealed a statistically significant improvement across all measures with the largest gains noted in the understanding of a client's progression as well as confidence in altering a client's plan of care $(\mu=3.76,3.97)$. Supervisors corroborated these data in their interviews. Supervisors consistently noticed students feeling more confident in their treatment strategies which led to clients feeling more comfortable with the care that they received, e.g. "I think it really carries over to confidence in the clinic, and confidence always translates to better care, when the patient is actually there. I have noticed an overall better continuum of care" (Supervisor \#3). Another supervisor noted, "I think they have a lot more confidence coming into the patient treatment session and I do think that they are providing a better service because of it” (Supervisor \#1).

Thirty-nine of forty-five first-year students commented on how Grand Rounds was helping to increase their familiarity with clients and their programs. Twelve communicated that they thought they could do more than just sit and listen in Grand Rounds. They expressed a desire to have a more active role. Five of the third-year students made this specific observation as well. They felt that the first-year students would be capable of a stronger participation role in Grand Rounds.

Forty of forty-three third-year students described the addition of Grand Rounds in a very positive manner using phrases like, "excellent idea”, "valuable experience”, "very effective”, and "great addition". They indicated that they felt the addition of Grand Rounds benefitted both the clients and the students. Three students specifically stated that they wished they had had this opportunity starting in their first year of study. They indicated that it would have helped their confidence and skill development.

\section{Teamwork}

Another pertinent theme noted through data analysis was teamwork and the subsequent mentorship between classes. The third-year students were able to initiate a mentorship role for the second and first-year students. 
I also found it helpful as a teaching, learning and collaborating experience with the PT I and II's because they would discuss certain patients and their specific plan of care and exercise programs and I think our class as PT III's, having been out on clinic, had really good ideas to bring to the table (Third-year student reflection \#18)

The first-year students also commented on how they were able to contribute right away to treatment of clients and noted ways that the second and third-year students were able to help them learn and work together in figuring out how to most effectively treat the client e.g. "I've learned techniques in Grand Rounds from the teachers and older PT students that help me deliver a better session with a patient" (First-year student reflection \#14). The supervisors saw evidence of the mentorship among students manifest in the Clinic as well, e.g. "The students are serving as mentors to one another in the clinic." (Supervisor \#1).

\section{Continuity}

Improved continuity of client care was addressed repeatedly through all forms of data collected, but was noted especially by third-year students, Clinic supervisors, and clients. Client opinion was captured with the client satisfaction survey. The question "Are you generally seeing the same therapist or group of therapists?" was met with an equal numbers of yes and no responses. When asked if the student therapists knew more about the client's specific case, 8 of 16 answered "yes". One client added, "It's great that they are all working together and knowing all the patients." (Client Satisfaction survey \#2).

The supervisors also recognized an improvement in students' understanding of client cases and effectiveness in establishing and working toward client goals. "I have noticed an overall better continuum of care" (Supervisor \#3). They noted that student therapists seemed to be more comfortable working with the clients and felt that the discussion of client cases during Grand Rounds led to better consistency with client care, e.g.. "I think Grand Rounds has been an excellent addition to client care continuity especially on the side of the student's experience". (Supervisor $\# 1)$.

Even first-year students began to connect with the importance of client progression and continuity of care.

"Grand Rounds has been helpful in staying in touch with the patients I have treated and seeing how they've progressed since the last time I saw them, as well as making sure I understand the plan of care for the patient I will see next time I go". (First-year student reflection \#37).

Third-year students noted how the implementation of Grand Rounds has led to increased involvement and discussion as a team on how to properly treat the clients and what ways the plan of care can be optimized. The third-year students pointed out that continued mentoring and interaction between experienced and novice students have led to an environment of information sharing that will benefit the clients' progression.

"I was happy to see such involved and engaging discussion about some of the patients we are treating in the clinic. The PT2s are doing a good job presenting their patients and 
updating us all on each patient's status and progression, while the PT3s seem to be doing a seamless job in sharing practical experience and suggesting ways in which we can do even better” (Third-year student reflection \# 9).

\section{Discussion and Conclusion}

In general, there was positive feedback from all participants in the study. The first-year students appreciated the introduction to therapy terms and treatment progression early in their curriculum, the second-year students felt more comfortable and confident with skills and program progression, and the third-year students were proud to share personal experiences from their clinical experiences to help mentor the younger students and assist with the progression of client programs. The supervising therapists also noted an increase in student confidence. The clients were ambiguous on whether they saw more familiar faces but were affirmative that they felt that the students were knowledgeable.

Recommendations to enhance the method emerged from the data as well. First-year students indicated that they felt they were ready to take a more active role in the Grand Rounds presentation. Third-year students recommended forming smaller case presentation groups within Grand Rounds composed of students across the classes. In these groups, the first-year students could present the basic information about the client, the second-year students present the majority of the case, and the third-year students provide mentorship and guidance to the case discussion. This mirrors the Grand Rounds model described by Rigby, Schofield, Mann and Bernstead (2012). Examples of this peer mentoring have been researched in the relationship between fellows and residents during training and education. Backes, Reber, Trittmann, Huang, Tobmlin, Moorehead, Bauer, Smith and Mahan (2011) found that $87.5 \%$ of residents in their study believed fellows to be important in their learning experiences. Another study with medical student participants revealed that peers viewed the senior medical students as "clinical teachers" (Doumouras, Rush, Campbell \& Taylor, 2015). This can be translated into the small groups during Grand Rounds by utilizing the third-year students as mentors or clinical teachers. Furthermore, the breakdown into smaller groups would allow for all students to play a more active role in their respective case presentations. This is also consistent with the findings of Rigby, Schofield, Mann and Bernstead's (2012) where both resident participation in analysis of the case study, and high levels of audience interaction, were strongly supported as key features for student learning. In smaller groups, students would be presented with more opportunities for client discussion and collaboration, thus leading to improved learning opportunities. Additionally, the Delphi study identified value in giving leadership responsibilities to the residents. The Student Board could appoint a student to serve as a teaching assistant alongside the Clinic supervisor / adjunct faculty member. This role could provide a leadership opportunity to the student leader as well as increase student participation.

While the evaluation showed that students experienced a significant benefit with the addition of teams and Grand Rounds, it was not as conclusive on the benefit to the clients. This could be because clients are still seeing many different student physical therapists and although the students on that team now have a better understanding of that specific client, the number of students that clients might see remains large. Consideration should be given to further narrow the number of potential student physical therapists that the client could see. In addition, client satisfaction surveys may not have adequately captured the client experience. First, only four questions specifically addressed the addition of teams and Grand Rounds; second, only 16 clients 
experienced the Clinic prior to the initiation of Grand Rounds as well as during Grand Rounds; and third, the survey did not sufficiently call for clients to respond in depth or elaboration.

As for the positive response that the second-year students demonstrated in the pre and post surveys, it is impossible to distinguish if their improved perceptions of their competence are a result of Grand Rounds or if they are a product of increased knowledge gained from the curriculum. In the 8 months of the Grand Rounds trial, the second-year students were also participating in 8 months of additional curricular coursework. We cannot know for sure that the implementation of teams and Grand Rounds was the cause for the improvements in the pre and post surveys. It is also interesting to note that this study can no longer be exactly replicated in this particular AMA program, as Grand Rounds is now in the curriculum and control groups that have not experienced Grand Rounds no longer exist. The evaluators would be unable to obtain pre-implementation data.

The model of Grand Rounds as described by Rigsby, Schofield, Mann and Bernstead (2012) proved to be an effective way to actively engage physical therapy students of all levels in a collaborative discussion of client cases furthering their confidence and effectiveness in advancing the physical therapy programs of clients in a student-run pro bono clinic. The model encouraged teamwork and collaboration with students mentoring one another within Grand Rounds as well as in the Clinic. In addition, several recommendations emerged from the evaluation to further improve the model. Specifically, Grand Rounds will be revised to give the first-year students specific roles and responsibilities in reporting on basic client case information and small groups will be formed to go over a case. These groups will consist of first, second, and third-year students to allow for greater mentorship.

The findings of this evaluation may be applicable to other physical therapy programs where opportunities for client care within the curriculum exist. The current program evaluation did not effectively measure the client experience or capture client clinical outcomes. The next program evaluation should focus on revision of the client satisfaction survey and institution of standardized client outcome measures to capture the effectiveness of the physical therapy program. The secondyear students completed a Likert-scale survey and had less opportunity for open-ended response than the first and third-year students. Future program evaluation should allow the second-year students opportunity to openly reflect on ways that Grand Rounds might be improved as well. Overall, the program evaluation proved very insightful and will lead to positive changes in the method. The institution of teams and Grand Rounds was effective in facilitating student learning and in moving clients toward more continuity in their care. 


\section{Appendix 1. Case Presentation Template}

\section{Client Grand Rounds Guide}

Team: Client:

Date:

\section{Student Therapists:}

\section{Background}

Name, Age, Gender, Diagnosis:

Date of onset, Mechanism of injury, History of symptoms:

Course of treatment prior to pro bono clinic:

Social History: (occupation, support system)

Date of eval, \# of visits to date, cancel/no show:

Current Status / Clinical Decision Making

Present interventions:

Current response to interventions:

Clinical Assessment:

Prognosis / Progression / Clinical Decision Making

Progression for the next three weeks:

Anticipated Discharge Week:

Discharge Concerns / Preparation:

Other: Updated script? / Communication?/ Re-eval needed?

Other concerns? / Important things to note?

\section{Action Steps: What and Who Responsible}




\section{Appendix 2. Third-Year Student Reflection}

PT715 Teaching and Learning Grand Rounds Reflection.

Attend and participate in the Grand Rounds meetings for you team. Reflect upon the experience. What went well? What went not so well? What is your overall assessment of the Grand Rounds experience? Please include any suggestions for improvement.

\section{Appendix 3. Second-Year Student Therapist Pre and Post Survey}

Please evaluate the following statements.

1. I have adequate knowledge of my client's condition / impairment prior to treating them at the clinic.

Strongly Disagree $\quad$ Disagree $\quad$ Neither Agree Agree Strongly Agree nor Disagree

2. I have an adequate amount of time to learn all that I need about my client prior to their arrival via chart review and WebPT.

Strongly Disagree $\quad$ Disagree $\quad$ Neither Agree Agree Strongly Agree nor Disagree

3. I am knowledgeable of my client's progression in their program plan.

Strongly Disagree $\quad$ Disagree $\quad$ Neither Agree Agree Strongly Agree nor Disagree

4. I feel confident in making alterations to my client's plan to improve their plan of care.

Strongly Disagree $\quad$ Disagree $\quad$ Neither Agree $\quad$ Agree $\quad$ Strongly Agree nor Disagree

5. I am confident in my ability to treat my client's specific case / pathology.

Strongly Disagree Disagree $\quad \begin{gathered}\text { Neither Agree } \\ \text { nor Disagree }\end{gathered} \quad$ Agree $\quad$ Strongly Agree




\section{Appendix 4. First-Year Student Reflection Questions}

Please complete the survey about the Grand Rounds meetings that you attended last semester. Your participation will help us improve the Grand Rounds experience.

I find Grand Rounds valuable.

Strongly Agree $\quad$ Agree $\quad$ Neutral Disagree $\quad$ Strongly Disagree

What did you find valuable about Grand Rounds?

Grand Rounds is a waste of my time.

Strongly Agree $\quad$ Agree $\quad$ Neutral $\quad$ Disagree $\quad$ Strongly Disagree

How could Grand Rounds be improved in general?

What could be done to improve your experience as a first-semester, first-year student in Grand Rounds?

Please feel free to give us any additional feedback here.

Thank you for your participation.

Journal of the Scholarship of Teaching and Learning, Vol. 17, No. 3, July 2017.

josotl.indiana.edu 
Black, Bauer, Spano, Voelkel, and Palombaro

\section{Appendix 5: List of Supervisor Questions}

Since the implementation of student treatment teams and grand rounds meetings:

1. What types of changes, if any, have you observed in the student therapists' knowledge of their patient and case?

2. Have you noticed any change in the student therapists' confidence during treatment? If yes, how so?

3. Have you noticed a change in patients' attitudes during therapy? If yes, how so?

4. What types of changes, if any, have you observed regarding the quality and continuum of patient care?

5. What types of changes, if any, have you observed in the efficiency of patient visits?

6. Is there anything else you would like to comment on?

Journal of the Scholarship of Teaching and Learning, Vol. 17, No. 3, July 2017.

josotl.indiana.edu 
Black, Bauer, Spano, Voelkel, and Palombaro

\section{Appendix 6: Client Satisfaction Survey}

\section{Client Satisfaction Survey}

We would like to know how you feel about the services we provide so we can make sure we are meeting your needs. Your responses are directly responsible for improving these services. All responses will be kept confidential and anonymous. Thank you for your time.

Your Age : Your Biological Sex is :

Your Race/Ethnicity (please check all that apply)

Asian __ Hispanic or Latino (All Races) __ White (Not Hispanic or Latino) Pacific Islander Black/African American American Indian/Alaska Native Unknown

Your Gender is : (ie. Male, female, transgender, etc.)

\begin{tabular}{|c|c|c|c|c|c|}
\hline & $\begin{array}{c}5 \\
\text { Great }\end{array}$ & $\begin{array}{c}4 \\
\text { Good }\end{array}$ & $\begin{array}{c}3 \\
\text { Ok }\end{array}$ & $\begin{array}{c}2 \\
\text { Fair }\end{array}$ & $\begin{array}{c}1 \\
\text { Poor }\end{array}$ \\
\hline $\begin{array}{l}\text { Ease of getting care: } \\
\text { Ability to get in to be seen }\end{array}$ & & & & & \\
\hline Hours Center is open & & & & & \\
\hline Convenience of Center's location & & & & & \\
\hline Prompt return of calls & & & & & \\
\hline Time in waiting room & & & & & \\
\hline Time in exam room & & & & & \\
\hline $\begin{array}{l}\text { Staff: } \\
\quad \text { Provider (PT/Student PT) Listens to you }\end{array}$ & & & & & \\
\hline Takes enough time with you & & & & & \\
\hline Explains what you want to know & & & & & \\
\hline Gives you good advice and treatment & & & & & \\
\hline Are friendly and helpful to you & & & & & \\
\hline Answer your questions & & & & & \\
\hline $\begin{array}{l}\text { Cost of Services (\$5/visit): } \\
\text { What you pay }\end{array}$ & & & & & \\
\hline
\end{tabular}

Journal of the Scholarship of Teaching and Learning, Vol. 17, No. 3, July 2017. josotl.indiana.edu 
Black, Bauer, Spano, Voelkel, and Palombaro

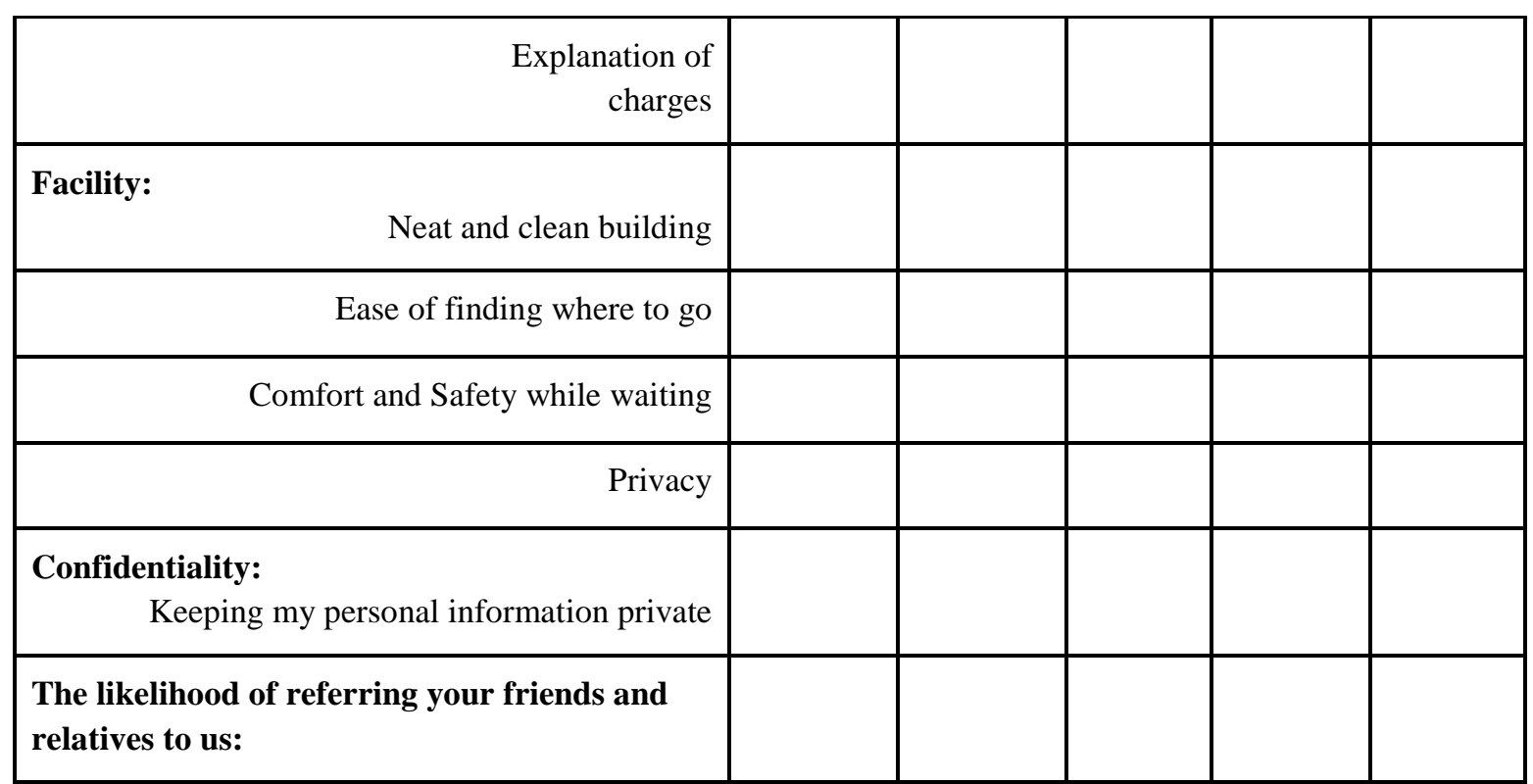

What do you like best about our Clinic?

What do you like least about our Clinic?

What suggestions do you have for improvement?

How comfortable are you with working with a student physical therapist?

Do you feel like you are seeing the same general group of student physical therapists?

Do you feel like the student physical therapist has adequate knowledge of your case?

In regards to the new teams, do you have any general feedback on your experience?

Thank you for completing our Survey!

Journal of the Scholarship of Teaching and Learning, Vol. 17, No. 3, July 2017.

josotl.indiana.edu 


\section{References}

Backes, C.H., Reber, K.M., Trittmann, J.K.B., Huang, H., Tobmlin, J., Moorehead, P.A., Bauer, J.A., Smith, C.V., Mahan, J.D. (2011). Fellows as teachers: a model to enhance pediatric resident education. Medical Education Online, 16: 7205 doi: 10.3402/meo.v16i0.7205.

Doumouras, A., Rush, R., Campbell, A., Taylor, D. (2015. Peer-assisted bedside teaching rounds. Clinical Teacher [serial online],12(3):197-202. Available from: Education Research Complete, Ipswich, MA. Retrieved October 18, 2015.

Goetz, C.G., Bonduell, M., Gelfand, T. (1995). Charcot: Constructing Neurology. New York: Oxford University Press.

Hebert, R.S., Wright, S.M.(2003). Re-examining the value of medical grand rounds. Academic Medicine,78(12):1248-52.

Hull, A.L., Cullen, R.J., Hekelman, F.P. (1989). A retrospective analysis of grand rounds in continuing medical education. Journal of Continuing Education Health Professional,9(4):25766.

Laskaratos, F.M., Wallace, D., Gkotsi, D., Burns, A., Epstein, O. (2015). The educational value of ward rounds for junior trainees. Medical Education Online, 20: 27559 http://dx.doi.org/10.3402/meo.v20.27559.

Medicine Net. (2015). Definition of Grand Rounds. Retrieved December 29, 2015 from http://www.medicinenet.com/script/main/art.asp?articlekey=40370.

Merriam Webster Dictionary. (2015). Definition of Grand Rounds. Retrieved December 29, 2015 from http://www.merriam-webster.com/medical/grand\%20rounds.

Parissopoulos, S., Timmins, F., Daly, L. (2013). Re-exploring the ritual of the ward round. British Association of Critical Care Nurses, 18(5):219-221.

Richards, J., Schwartzstein, R., Irish, J., Almeida, J., Roberts, D. (2013). Clinical physiology grand rounds. The Clinical Teacher [serial online]. 10(2):88-93. Available from: MEDLINE, Ipswich, MA. Accessed October 18, 2015.

Rigby, H., Schofield, S., Mann, K., Bernstead, T. (2012). Education Research: An exploration of case-based learning in neuroscience grand rounds using the Delphi technique. Neurology, 79:e19-e26.

Stanyon, M., Khan, S.A. (2015).Requiem for the grand round. Clinical Medicine,15(1): 10-11.

Van Hoof, T.J., Monson, R.J., Mafdalany, G.T., Giannotti, T.E., Meehan, T.P. (2009). A case study of medical grand rounds: are we using effective methods? Academic Medicine. 84(8):1144-1151. 
Black, Bauer, Spano, Voelkel, and Palombaro

Chester Community Physical Therapy Clinic Mission Statement. Retrieved December 29, 2015 from www.chestercommunitypt.com.

Journal of the Scholarship of Teaching and Learning, Vol. 17, No. 3, July 2017.

josotl.indiana.edu 